\title{
LA CUESTION DE LA USURA EN EL CONTEXTO DE LA POBREZA VOLUNTARIA
}

Celina A. Lértora Mendoza*

SINTESE - A tradição cristã, referindo-se a Jesus e aos apóstolos, desenvolveu um ponto de vista muito restrito quanto ao lucro advindo do dinheiro. Nos séculos XIII e XIV, os religiosos que faziam votos de pobreza não só individual, mas também coletiva, defrontaram-se com teorias antigas em uma nova situação econômico-social e em seus tratados desenvolveram teses que diferiam do legado anterior.
ABSTRACT - Based on Jesus and the apostles, the Christian tradition has developed a very narrow viewpoint about the profit of money. In the 13th and 14th centuries, monastic people take the vow of poverty not only individually, but also collectively, living now in a new economical and social situation. Therefore they have also developed new ideas about poverty, different from the ancient legacy.

\section{Introducción -}

Se ha observado el hecho un tanto paradojal de que precisamente quienes hicieron de la pobreza voluntaria el estado propio de su vida, sentaron las bases éticas de una teoría capitalista del dinero. ${ }^{1}$ También se sabe - no es nada nuevo que la recepción de las concepciones patrimoniales romanistas determinó una significativa variación en la normatividad de las relaciones económicas tardomedievales. Finalmente, debemos tener en cuenta que las controversias sobre la pobreza voluntaria de los ss. XIII y XIV produjeron un material teórico eclesiástico que si bien se refiere en lo esencial a los frailes decididos a aplicar a su comunidad los consejos evangélicos (y que, por tanto, no es inmediatamente aplicable a toda la sociedad) de hecho tuvo influencia en el tratamiento ético y jurídico de algunas cuestiones.

La usura es una de esas cuestiones influídas por estos tres factores. ¿Cómo juegan en la elaboración de una nueva visión sobre los contratos y las relaciones económicas bilaterales, que tanta importancia tendrían en la modernidad? Sin

- CONICET - Buenos Aires.

1 Lester Little, "L'utilité sociale de la pauvreté volontaire" en Michel Mollat (ed) Etudes sur l'histoire de la pauvreté, Paris, 1974, T.1: 447-459 y Pobreza voluntania y economia de beneficio en la Europa Medieval, Madrid, Taurus, 1980, p. 7.

\begin{tabular}{|l|l|l|l|l|l|} 
VERITAS & Porto Alegre & v. 40 & $\mathrm{n}^{2} 159$ & Setembro 1995 & p. $583-598$ \\
\hline
\end{tabular}


duda es un proceso tan complejo y lleno de matices, que no se puede abordar en forma exhaustiva aquí. En esta comunicación me centraré en dos aspectos que considero particularmente significativos: la introducción del tema de la función social del dinero como medio de cambio y la reelaboración del concepto de propiedad monetaria.

Antes de abordar estos aspectos en la literatura franciscana tardomedieval, es importante señalar el estado de la cuestión a mediados del s. XIII.

\section{El estado de la cuestión}

A mediados del s. XIII la cuestión de la usura tenía una larga tradición. Los franciscanos reciben una elaboración del problema ${ }^{2}$ que reducida a su esquema fundamental tomaría la siguiente forma:

1. En primer lugar la conceptualización de la usura, en general y particularizadamente

2. Cuestión ética de la usura que a su vez se integra con dos consideraciones: a. su ilicitud; b. restitución. Ambas cuestiones se implican pero son distintas.

La conceptualización de la usura se presenta en dos contextos, que las controversias mendicantes aproximan definitivamente. Por una parte, la cuestión de la pobreza de Cristo plantea el problema moral de la riqueza (posesión de bienes exteriores) en sí misma. Por otra, en el contexto de la moral de las relaciones económicas, la teoría del justo precio proporciona otro abordaje al tema del interés y de la usura. $^{3}$

La pobreza de Jesús es un hecho que consta en las Escrituras. Desde los primeros pasos del cristianismo se han sacado diferentes consecuencias del mismo. ${ }^{4}$ Ya Pablo la había propuesto como un modelo a imitar (2 Cor. 8, 9). La dialéctica paulina asume que Cristo, siendo rico se hizo pobre a fin de enriquecernos en virtud de su pobreza. Naturalmente está aquí presente todo el tema de la kénosis pero también hay una obvia lectura descriptiva de actitudes y situaciones de "pobreza" que son referidas modélicamente: no asirse a nada (una de las tentaciones en el desierto es precisamente la riqueza), servir, humillarse, obedecer, actitudes todas que la sociedad antigua conectaba con la situación social de pobreza o carencia de bienes económicos. Sin embargo, y aunque la pobreza y el desprendimiento integraron desde el principio los ideales de la perfección cristiana (sobre todo en las concepciones eremiticas), debemos aguardar hasta los ss. IV y V para hallar una elaboración teológica del tema con San Hilario, San Basilio, San Ambrosio, San Agustín y otros Padres que conectan las ideas paulinas a la figura salmista del "siervo de Yahvé". La paradoja de un Dios nacido pobre, con figura de humilde siervo, sin gloria ni riquezas y que nos redime con una muerte afrentosa, es un tema

2 Este punto fue estudiado por Giacomo Todeschini, "Oeconomica Franciscana. Proposte di una nuova lettura delle fonti dell'etica economica medioevali", Rivista di Storia e Letteratura Religiosa 12, 1976: 15-77.

3 Las relaciones en clave teológica entre mercado y justo precio fueron estudiadas por A. Spicciani: La mercatura e la formazione del prezzo nella riflessione teologica medioevale, Roma, Ac. Lincei, 1977.

4 Un estudio en J. Leclerq OSB, "Les controverses sur, la pauvreté du Christ", en M. Millat, Etudes... cit t. 1, p. $45-55$. 
que se repite en los Concilios y en las admoniciones a los emperadores jugando también su parte en las controversias cristológicas. En todos los casos se presenta como manifestación del misterio divino de la Encarnación: la kénosis implica una "pobreza" ontológica que en la existencia real de Jesús se traducirá como pobreza económica y social. Ser pobre en sentido real es, pues, en sí mismo, un signo de la kénosis y conecta misteriosamente con los designios salvíficos de Dios. Esta idea, que hallamos actualmente desarrollada en la "teología del rostro del pobre" tuvo una larga y subterránea historia, de modo que su emergencia en las controversias mendicantes adquiere un sentido particular por la etapa histórica en que se da: la aparición de un nuevo tipo de pobres y de ricos en las ciudades bajomedievales.

Los Padres habían concluído que la pobreza de hecho (la carencia de bienes económicos) es en sí misma una manifestación de la pobreza ontológica, condición a su vez de la kénosis y la redención. Con esto se situaba la cuestión en un terreno que admitía una doble lectura: una, más interiorista, que continúan los monjes durante el medioevo, y otra, más exteriorista, que emerge en las controversias del s. XIII.

Los mendicantes pusieron el acento en el aspecto exteriorista de la cuestión y sostuvieron que no sólo Jesús, como Verbo encarnado, no había poseído bienes, sino que quien quisiera verdaderamente imitarlo, debería carecer de ellos como una condición inexcusable. ${ }^{5}$ Como para la mentalidad religiosa de la iglesia todos los hechos de Cristo son modélicos para nosotros, la cuestión tomó la forma de una discusión histórica acerca de si Jesús había tenido bienes que pudieran llamarse propios o no, asumiendo que en cualquier se trataba de un hecho voluntario. De allí la apelación mendicante a la pobreza voluntaria (imitación de Cristo). Los teólogos franciscanos más importantes del s. XIII, como Ricardo de Mediavilla y San Buenaventura, son explícitos en el sentido de que Cristo, rey de todo, fue voluntariamente pobre, pero también aceptan que su realeza como señor de todo fundamenta la propiedad eclesiástica. Esta conciliación, que no fue aceptada por los espirituales más extremos, sienta las bases de un cierto dualismo moral: los teólogos del s. XIII son ya conscientes de que las reglas morales en extremo rigurosas de la pobreza absoluta no son aplicables a quienes tienen un patrimonio que atender. Precisamente el hecho de que la pobreza de Cristo haya sido voluntaria, es interpretado como un modelo de perfección absoluto que no todos los cristianos están obligados a seguir (Sent. IV, d. 24, p. 1, a. 1, 3). Por lo tanto, si bien la renuncia a todos los bienes materiales es uno de los modos más eficaces de participar en la realeza de Cristo, sin duda no es el único ni es imprescindible. La consagración eclesiástica de esta tesis moderada, que los espirituales que permanecieron en la ortodoxia cristiana terminaron por aceptar, consagró también indirectamente el dualismo moral dentro del cristianismo en las cuestiones económicas.

5 Esta idea, en cuanto funcionara normativamente, abriria la controversia con los seculares, incluso antes de las definiciones curiales romanas sobre la cuestión del uso. A pesar de las limitaciones téricas impuestas por el magisterio, la negativa mendicante a detentar dominio creó une situación objetivamente conflictiva con la tradición cleriçal, como lo ha señalado $\mathrm{H}$. Lippens: "Le droit nouveau des Mendicants en conflict avec le droit coutumier du clergé seculier, du concile de Vienne à celui de Trente", Archivum Franciscanum Histonicum 47, 1954: 241-292. 
Es así que el II Concilio de Lyon, pocos años después (en 1274) retoma y reitera estas consideraciones en dos Constituciones que tratan específicamente la usura. La Constitución 26 reitera la 25 del Lateranense III que debe ser inviolablemente obedecido bajo anatema divino. Quienes lo violen serán penados con excomunión si son individuos, con suspensión, si son clérigos y con interdicto, si son comunidades (COD 304, 5; Schroeder 355-6). Por su parte la Constitución 27 establece la obligación de restituir por el interés ilegítimo, lo que debe hacerse por medio de notario competente. Los religiosos no deben admitir a los usureros notorios bajo las penas establecidas en el Lateranense III, ni los sacerdotes pueden darles la absolución mientras no restituyan (COD 305-6, Schroeder 357).

Finalmente, ya en pleno s. XIV, el Concilio de Vienne (1311-1312) enfoca un problema que seguramente se había agudizado: la resistencia a restituir y quizá un cuestionamiento al concepto mismo de usura como algo ilegítimo y anticristiano. $\mathrm{Su}$ Decreto 29, que reitera la obligación restitutiva, establece que quien - incluso por error - afirme que no practica la usura debe ser penado como hereje, y se ordena a los ordinarios y a los inquisidores proceder contra ellos en acusación pública por sospecha de herejía (COD 360-12, Schroeder 401). Esta es la medida más fuerte tomada en estos tiempos contra tal práctica, ya que se la incluye entre los delitos con jurisdicción inquisitorial. Esto nos da la pauta de que a principios del s. XIV́ las ideas sobre el tema no eran claras en la cristiandad, ya que el decreto deja entrever que muchos cristianos no consideraban ilegítimo el préstamo a interés. Por otra parte, las expresiones usura e interés ilegítimo que se usan como equivalentes, suponen a contrario sensu la existencia posible de un interés legítimo. Este es un tema sobre el que discutieron los escolásticos.

Los posteriores Concilios Ecuménicos de los dos siglos siguientes (de Constanza en 1414-18, de Basilea-Ferrara-Florencia-Roma de 1431 a 1445 y el V de Letrán de 1512 a 1517) no innovan sobre este particular. Fueron Concilios signados por otras preocupaciones. De la falta de normativas nuevas no podemos extraer la consecuencia optimista de que los decretos anteriores se complieron. Más bien hay que pensar que la situación continuó su marcha hacia un progresivo reconocimiento del valor económico y de la justicia de las transacciones financieras, justicia que buscará sus propias reglas en los tratadistas del s. XV en adelante, ayudada sin duda por la propensión casuística que signa la moral eclesiástica en la modernidad.

\section{Análisis de la posición mendicante}

Lester Little ha descrito la compleja relación entre pobreza voluntaria y economía de mercado en estos términos: "Parece que hemos arribado a dos paradojas: primero, los monjes, completamente desprovistos de poder, legitimaron la violencia organizada; después, frailes carentes de recursos justificaron el comercio y la adquisición de dinero. Cada una de estas situaciones presenta un aspecto incontestablemente paradojal, pero ninguna contiene una contradicción realmente insoluble. Los hombres siempre buscan una solución a los problemas que los atormen$\tan$ y lo hacen de diversas maneras que no son todas razonables y ni siquiera concientes [...] buscaron seguir a Cristo, que de rico se hizo pobre (2 Cor. 8, 9). Pero, como "rico" y "pobre" tuvieron significaciones diferentes en las dos sociedades dife- 
rentes, las dos formas de pobreza voluntaria que surgieron de ellas fueron inevitablemente diferentes una de otra". ${ }^{6}$ Esta consideración me introduce en el propósito del trabajo. No se trata de cuestionar la voluntad de pobreza de los mendicantes moderados, ni de agudizar las tensiones entre las facciones que dividieron a los franciscanos en aquella época, sino señalar de qué manera, partiendo de un convencimiento inquebrantable en la excelencia de la pobreza voluntaria tal como cada grupo la entendia, ${ }^{7}$ se podía llegar y se llegaba realmente, a una justificación del uso del dinero y a una nueva visión del antiguo problema de la usura, cuyas resonancias continuarian en la modernidad. $Y$ digo que las diferencias internas en cuanto a la pobreza voluntaria era irrelevante porque el tratamiento de los problemas del comercio y el intercambio, tareas en que ninguno de los grupos se metía a título propio, no difiere mayormente y el mejor ejemplo de ello es precisamente un filoespiritual como Pedro Juan Olivi. ${ }^{8}$

\section{A. La función social del dinero como medio de cambio}

Considero que una de las novedades producidas entre fines del s. XIII y mediados del XIV en virtud de las nuevas ideas mendicantes es la consideración sistemática de la función del dinero como medio de cambio. Esto tiene que conectarse con variaciones significativas en la composición patrimonial de la riqueza. Durante los siglos feudales, la función del dinero como medio de cambio fue muy limitada. Quizá por eso mismo el problema del uso del dinero no se planteó entre los monjes con tanta agudeza como entre los frailes. Los monasterios altomedievales, integrados en una economía agraria y feudal, tenían otro tipo de problemas a la hora de vivir en concreto la pobreza evangélica. Para los monjes, la pobreza consistia fundamentalmente en un desprendimiento de los signos exteriores de poder (los que identificaban a los nobles guerreros y a los caballeros de armas) y quizá por eso pusieron más el acento en la pobreza individual, la humildad personal y la parsimonia. Ser pobre quería decir más bien ser pacifista y humilde que carecer de objetos de propiedad o de uso. El monje se definía como tal sobre todo por su perfil orante, en contraposición al activismo del guerrero, más bien que por su carencia material. Por tanto esta pobreza de espiritu no impedia que la comunidad poseyera bienes materiales puesto que ellos eran secundarios a la hora de determinar el concepto de pobreza voluntaria y de imitación de Cristo. Desde el punto de vista de su

6 "L'utilité sociale de la pauvreté volontaire" cit, p. 458-9.

7 Aunque en otro sentido los matices no son irrelevantes, en general los mendicantes vinculaban la pobreza voluntaria a los tres consejos evangélicos: superación de la soberbia con la humildad, de la lujuria con la castidad y de la avaricia con la pobreza. Pero de ello no se sigue que las riquezas sean malas en si (v. Gustavo E. Podestá "Avaricia, propiedad privada y bienes superfluos", Teologia 12, n. 25-26, 1075: 42-73). San Buenaventura es explícito en indicar que el peligro de las riquezas es ser ocasión de pecado, no que sean pecado por si mismas (Apol. paup. c. 7, n. 2). Las ideas bonaventurianas fueron en gran parte recogidas por el Papado en la cuestión franciscana, como ha mostrado Venancio Maggiani OFM en "De relatione scriptorum quonumdam a S. Bonaventurae ad Bullam 'Exiit' Nicolai III (1270)", Archivum Franciscanum Historicum 5, n. 1, 1912: 3-21, donde demuestra con paralelos textuales la concordancia entre los escritos de S. Buenaventura y la Encíclica.

8 Sobre este punto v. el estudio de G. Todeschini "Oeconomica Franciscana II: Pietro di Giovanni Olivi come fonte per la storia dell'etica economica medievale", Rivista di Storia e Letteratura religiosa 13, 1977: 461-494. 
sostén vital, el monacato adhirió a los sistemas agrarios y por tanto se proveyó de sustento mediante el trabajo, casi sin intervención financiera. Quedaba a criterio de la perfección de cada individuo el grado de complacencia con los deleites que proporcionan las cosas (tanto más santo se es, cuanto menos aficionado a ellas) y a cargo de los reformadores establecer reglas más rigurosas en las comunidades cuando el lujo comunitario traspasaba ciertos límites. Aunque la "pobreza" de los monjes fue razonablemente puesta en entredicho por los mendicantes, lo que no pudo ni puede decirse es que la cuestión del dinero haya sido para ellos un grave problema de conciencia, sencillamente porque no se daba el caso.

La importancia económica del dinero crece en igual proporción que el desarrollo comercial, el cual a su vez resulta paralelo al proceso de urbanización y a la profunda transformación del sistema político social feudal..$^{9}$ No voy a entrar aquí en la discusión sobre este proceso, que excedería los marcos de la propuesta, pero sí es preciso señalar que el conjunto de estos factores - como quiera se interprete su interacción - determinan de hecho la aparición de una economía notoriamente financiera, lo que sin duda es una novedad de fines del s. XIII en adelante, al menos en esa magnitud. Así como los monjes se adaptaron al sistema económico feudal, los mendicantes hicieron lo propio en las ciudades. La cuestión de la pobreza entendida como carencia real de posesiones materiales incluia la posesión del dinero, pero en la medida en que el dinero mismo era una cuestión nueva, también resultaría un abordaje distinto a su respecto.

Las razones de que el problema monetario tenga un tratamiento específico incluso en el contexto de la controversia mendicante, deben buscarse por distintos lados. A riesgo de simplificar, pero intentando una captación comprehensiva del fenómeno, diría que estas razones son de dos tipos, y responden a la necesidad, por parte de los mendicantes, de dar respuestas a dos tipos de interlocutores. Por una parte están los interlocutores intraeclesiásticos, con quienes se plantea la cuestión de los preceptos evangélicos y los estados de perfección. Frente a ellos, los mendicantes esgrimirán conceptos muy afinados en el tema del dominio vs. uso y los límites permisibles del uso mismo. Por otra parte están sus fieles, su clientela, que es netamente urbana y postfeudal, sea rica o pobre. Los fieles que acuden a los mendicantes pueden ser tanto ricos mercaderes y banqueros (incluso ya más ricos que los nobles) como mendigos y marginales absolutamente carenciados, pasando por un amplio arco socio económico (pequeños mercaderes, artesanos, trabajadores serviles, campesinos empobrecidos y migrantes). A todos se debia predicar el mismo evangelio y proponer un modelo cristiano de vida. Sin embargo las condiciones reales de cada grupo eran muy diferentes y mucho más variadas que las dos o tres opciones que se presentaban en la época feudal. El hecho de que la predicación estuviese ligada a la penitencia (conforme a las directivas del IV Concilio de Letrán) vincula esta cuestión, de modo natural, con la consideración práctica de la amplitud y límites de la restitución, asunto en que el pensamiento franciscano es particularmente novedoso.

9 Little ("Pobreza voluntaria y economía de beneficio", cit, p. 40) hace observar que mientras una comunidad agricola se mide por centenares de personas, una urbana se cuenta por millares. La cuestión del número y sus efectos multiplicadores se hace evidente. 
Por otra parte la sociedad urbana destinataria de la acción pastoral mendicante tenia caracteristicas distintas de la feudal en cuanto a su movilidad y composición. Los avatares del comercio y de las nuevas formas de producción de la riqueza determinaban rápidos ascensos y descensos sociales y económicos, así como un cierto sentimiento de inseguridad y una brecha muy notable entre pobres y ricos. Esto determinaba que los asuntos de conciencia no pudiesen tratarse en forma general para toda una comunidad o un estamento, sino que debieran resolverse conforme a las condiciones particulares muy a menudo harto diferentes entre personas próximas. No sólo los clérigos que juzgaban las cuestiones de conciencia sino también los mismos laicos que hacían su examen de conciencia debían tener ideas más matizadas de sus responsabilidades y deberes morales. La relación entre interioridad y exterioridad se va complicando porque las situaciones imprevisibles provocan efectos no sólo no queridos, sino ni siquiera previstos, y al mismo tiempo se aumenta la necesidad de previsiones específicas, lo que va convirtiendo la cuestión moral en una situación cada vez más interior y personal, no transferible, puesto que casi nadie está en igual situación real que su vecino. Esta es, a mi criterio, una de las razones por las cuales la moralidad monacal, muy uniforme, resultó inadecuada a las nuevas condiciones, lo que determinó la aparición de otro tipo de problemas morales, vinculados a la intención y la delimitación de la responsabilidad en virtud del principio de la previsibilidad.

Otra de las situaciones que la mendicancia debió asumir es la justificación moral de la actividad comercial (economia de mercado). Mientras dicha actividad fue secundaria en relación al grueso de la población y a las necesidades de supervivencia de las sociedades, pudo caracterizarse en forma simplificada e incluso negativa desde el punto de vista cristiano. Pero ya en pleno s. XIII estaba claro que las nuevas formas societarias, urbanas e incipientemente nacionales, no podrían sobrevivir sino en virtud de intercambios económicos. ${ }^{10} \mathrm{El}$ autoabastecimiento, situación ideal del alto medioevo, era absolutamente inviable en el nuevo sistema social. El antiguo menosprecio de los comerciantes (incluídos los tiempos paganos) debió dar paso a una justificación moral de su actividad.

Este es un punto que debe ser analizado con cuidado. Desde tiempos patrísticos, la idea de que el dinero es instrumento del demonio (instrumento de tentación) había producido una cierta equiparación entre comerciantes y malvivientes, idea que todavia respiran algunos textos posteriores a esta época (por ej. la obra de Bobadilla en España). La prohibición del préstamo a interés tenía pues dos puntas: por una parte se justificaba porque parecia violar la regla del justo precio; por otra, porque siendo el dinero malo en sí mismo (sólo un mal tolerado), su producto propio nunca podría ser bueno. Finalmente, era natural vincular el interés a la avaricia, porque era visto como una búsqueda del dinero por el dinero mismo. Ni qué decir que la historia de Judas proporcionaba un elemento escriturístico a favor del recelo contra toda transacción monetaria. En este contexto, la justiticación moral del comerciante y del uso del dinero aparece como una de las novedades pastorales más importantes que han tenido como actores a los mendicantes. Las reglas para con-

10 Sobre las nuevas ideas políticas en el contexto urbano del s. 14 v. F. Martín Hernández, "Ideas de democracia en la baja Edad Media (de Juan de París a Guillermo de Ockham)", Carthaginensia 10, n. 17, 1994: 51-71. 
fesar y para hacer examen de conciencia propuestas por Raimundo de Peñafort, dominico, y Alejandro de Hales, franciscano, en la primera mitad del s. XIII, nos dan la pauta de que algo estaba cambiando profundamente en este punto: el comercio no es una actividad ilícita en sí misma, y sólo llegará a hacerlo si se violan ciertas reglas morales, situación que es establecida en confesión. Raimundo, que dió; a su tratado de moral una cierta inclinación casuística más propia de los juristas, enumera los pecados conforme a las categorías de vicios, y analiza los obstáculos para la confesión (miedo, vergüenza, vanidad y desesperación) y los medios para combatirlos. Su obra fue muy imitada, y posiblemente influyó también en escritos de derecho canónico que ordenan alfabéticamente los temas básicos, como el del franciscano Monaldo de Capo d'Istria, c. 1270.

Justificada la profesión del comerciante en el medio social en que actúa, es natural que el instrumento propio de su actividad, el dinero, sea también justificada, en la medida en que sirve a esa nueva función social. Esta restricción es muy importante porque precisamente es la que permitirá conjugar la antigua teoria del precio justo con la nueva realidad comercial por una parte y con la obligación de restituir por otra.

En esta conceptualización el dinero va apareciendo cada vez más en su función financiera y abstracta, desligándose de su soporte material, en un proceso que la historia económica llama de "desmaterialización" monetaria. Recordemos que en tiempos altomedievales, con la desintegración de la unidad carolingia, la acuñación de moneda se atomizó y sufrió el mismo proceso desintegrador que las demás actividades sociales. Cada moneda valía en un ámbito muy retringido, el sujeto a la jurisdicción acunante y fuera de ella en proporción al metal noble que contenían. Era un dinero que valía por sí mismo más que por lo que representaba y su acumulación producía riqueza independientemente de que produjera o no interés. En este contexto es natural no sólo que la usura no sea un problema detonante, sino aún que cualquier interés fuera considerado pernicioso, o al menos innecesario y que su obtención pueda calificarse de avarienta.

En el s. XIII asistimos a un nuevo proceso de alza monetaria: se acuñaron monedas de oro que dieron más vitalidad a la economía de intercambio por su mayor valor, lo cual centralizó; su control en las jurisdicciones más poderosas: los reyes de Francia, Inglaterra, Castilla y ciudades estados importantes. ${ }^{11}$ Las complejas relaciones en el uso de estas monedas dieron lugar a los banqueros, los instrumentos de cambio y los seguros. Cuando el grupo de estas nuevas profesiones se consolidó, podemos considerar definitivamente formado el tejido urbano, integrado por los productores circundantes, los artesanos (sector secundario) y el sector de servicios, constituido por los mercaderes, banqueros, empresarios y profesionales. Este sector terciario, como estamento nuevo, se servía espontáneamente del dinero como medio de cambio. La moneda con que se pagaban mercancías o servicios profesionales comenzaba a valer más bien por lo que significaba como posibilidad de obtener algo con ella, que por lo que valía en sí misma como material. De allí que no sólo el uso se considere inseparable del dinero, sino que el uso mismo determina su importancia como función social. Para apreciar este necesario cambio en la mentali-

11 Little, Pobreza voluntaria y economia de beneficio cit. p. 30-31. 
dad latina a partir del s. XIII, consideremos que no sólo se monetarizó la vida urbana, sino también la rural. La necesaria intervención del comercio para alimentar a las ciudades hizo que los campesinos abandonaran el trueque o el acopio de tipo feudal para plegarse a la organización de mercados, produciendo el efecto de que los terratenientes con tierras aptas para la producción intensiva se vieron muy favorecidos por el aumento de valor de sus propiedades. ${ }^{12}$ La ciudad no sólo enriqueció a los burgueses, sino también a los campesinos y propietarios que quedaron vinculados a ella en una economía de mercado.

En esta nueva sociedad el dinero es un medio de cambio que permite prescindir de particularidades personales y particulares, imposibles de controlar en las concentraciones humanas cada vez más numerosas. La universalidad del dinero y de los instrumentos de cambio inventados en consecuencia tenían una eficacia ostensible. El uso técnico del dinero producía un aumento progresivo y notable en el aumento de los bienes económicos contribuyendo al bienestar de todos los implicados en el sistema. Y aunque la brecha entre estos beneficiados y los marginados era cada vez mayor, la discusión no podía centrarse razonablemente en una restricción al uso técnico del dinero sino en la justa distribución de la riqueza, que fue el gran problema de la ética económica desde entonces hasta nuestros días. ${ }^{13}$

Debemos preguntarnos ahora como fue interpretado teóricamente este nuevo mundo económico que los mendicantes tenían a la vista, y de qué modo respondieron a los problemas de conciencia que se les planteaban. En primer lugar debemos decir que en las obras de esta época apreciamos la asunción de la nueva visión sobre el dinero y los medios de cambio. Los autores mendicantes no discuten la naturaleza del dinero sino que adoptan el punto de vista habitual en su sociedad, incluso cuando citan autores antiguos que tienen otra visión, produciendo un anacronismo que debe ser correctamente interpretado. El "dinero" que tienen en vista no es un dinero en abstracto, sino el tipo de dinero que de hecho ellos veían usar, así como las transacciones y contratos que mencionan son las propias de un medio urbano con muchas relaciones mercantiles, como se ve en los ejemplos que se ponen para ilustrar teorias y respuestas de autores más antiguos. Por lo tanto, considero que las adhesiones y las citaciones deben ser leídas en el contexto de una economia que acepta pragmáticamente la funcionalidad del uso del dinero.

Esta funcionalidad del dinero depende de reglas propias (que hoy estudia la ciencia económica) e independientes tanto de la voluntad personal de los sujetos como de las valoraciones morales que hagamos de ella o del dinero mismo. Por lo tanto, si se admite la licitud intrínseca de la posesión de bienes materiales y su obtención justa (extremo que quedó claramente definido por el magisterio eclesiástico luego de la polémica franciscana) entonces debemos extraer las consecuencias

12 Los historiadores sajones, como Little y R. G. Witt han estudiado este proceso especialmente en la zona norte de Europa.

13 Por otra parte, el pensamiento mendicante franciscano del s. XIII había incluido el tema de la justicia social entre los elementos esenciales de la legitimidad del sistema político. S. Buenaventura trató varias veces este punto (en Comm. Sent. y De perfectione evangelica). En las Collationes in Hexaemeron (V, n. 14-19) es explicito en cuanto a los principios generales de justicia como base del sistema del estado (conf. Hadrianus Borak OFMCap. "Principia doctrinae politicae apud S. Bonaventuram", Laurentianum 5, n. 4, 1964: 301320). 
morales de tal licitud. Creo que los tratados sobre la usura que pulularon entre los mendicantes entre fines del XIII, todo el XIV y el XV deben ser leídos en este contexto condicional vinculado a la discusión sobre la pobreza voluntaria y lo que ella implica. El tratado de Pedro Juan Olivi sobre la compraventa, la usura y la restitución puede ser considerado un excelente ejemplo de lo que quiero decir. ${ }^{14}$

Las novedades introducidas por los escolásticos en el pensamiento económico fueron muchas y algunas, aunque no se refieren directamente a la usura, deben ser mencionadas porque configuran el marco conceptual en que ella va a ser tratada.

La primera cuestión dilucidada y resuelta afirmativamente por los escolásticos fue la justificación ética de la propiedad privada. En un contexto de recelo hacia la apropiación individual, de exaltación de la propiedad común (canónigos regulares, monjes) o su ausencia (mendicantes) la teoria privatista, defendida incluso por frailes como Tomás de Aquino, debía tener importantes consecuencias. El Aquinate sigue y reafirma a Aristóteles en su justificación de la propiedad privada como necesaria para la vida buena y el orden social (Sum. Theol. 2a. 2ae, q. 66). En el mismo sentido se expide San Buenaventura, aunque insistiendo en que la propiedad absoluta es de Dios y la del hombre es derivada y administrativa (II Sent. d. 32, a. 3 q. 2 c). Admitida la propiedad, aparecen los problemas de su uso y su transmisión, pero ya como perfectamente normales y justificados en general: usar y transferir no puede ser algo ilegítimo en sí mismo, sino en todo caso según el modo cómo se haga. Las disquisiciones del s. XIV precisamente van orientadas a esa dilucidación.

La cuestión del uso se separó rápidamente de las fuentes jurídicas romanas para constituir un problema interno entre los mendicantes. La cuestión del mal uso se vincula a la del uso del mal (no es juego de palabras), puesto que mal uso sería en su sentido más fuerte hacer uso de lo malo. Para dilucidar si es o no legítimo usar algo malo los escolásticos distinguieron tres tipos de mal: físico, moral y teológico. Pensadores tan disímiles en otras cosas como San Buenaventura y Santo Tomás, coinciden aquí en muchos puntos. ${ }^{15}$ Ambos afirman que es lícito usar el mal físico, ordenando algo incompleto o defectuoso a los fines propios. El mal moral de culpa no es susceptible de uso, pero si el mal de pena (en esto coinciden pero con matices). Ambos admiten también que el mal moral (o pecado) ajeno puede usarse lícitamente pues el mal moral de un sujeto es un mal físico para un tercero. San Buenaventura se ocupó especialmente de las relaciones entre posesión y uso. Se puede usar de dos maneras: o como dueño o como vicario (como usa el siervo los bienes de su señor). La actitud del dominus se expresa más por una actitud interior que por la manifestación del uso (Apol. Paup. c. 7, ns. 37-39 y Exp. reg. c. 6, n. 11). En cuanto al uso en sí, se muestra restrictivo sólo en lo superfluo, lo cual se determina en cada caso (III Sent. d. 37, dub. 7). Es evidente que estas delimitacio-

14 Este tratado fue erróneamente atribuido a Gerardo de Siena y su autenticidad fue claramente establecida por Pacetti: "Un trattato sulle usure e le restituzioni di P. di G. Olivi falsamente atribuito a Fra Gerardo de Siena", Archinum Franciscanum Historicum 46, 1953: 448-457. Fue editado por G. Todechini con un amplio estudio preliminar, "Un trattato di economia politica francescana: il "De emptionibus et venditionibus, de usuris, de restitutionibus", di Pietro di Giovanni Olivi, Roma, 1980.

15 Para un estudio de sus similitudeds y diferencias v. José Ignacio Saranyana, "Santo Tomás y San Buenaventura frente al 'mal uso' (Ms. 52 folio lv de la Catedral de Pamplona"; Rivista di Filosofia Neo-scolastica 58, n. 2, 1976: 189-212. 
ne acotan bastante el tema del uso de lo malo e indirectamente transforman la cuestión de la usura en una pregunta por los límites de la licitud del uso del dinero.

En cuanto a la transmisión de la propiedad, la cuestión del precio justo cobró relevancia cuando las transacciones por dinero superaron y reemplazaron a las transmisiones feudales. Tanto los juristas civiles como los canonistas asumieron el principio romano del mercado libre. El Derecho Romano protegía esa libertad castigando los fraudes, es decir, la mala fe que ponía de hecho a una de las partes en manos de la otra. Toda transacción que no se atuviera al justo precio caía en sospecha de fraude, pero si lo había o no era una cuestión de hecho a dilucidar en cada caso. No todo precio diferente y mayor que el precio justo era automáticamente fraudulento y por eso era necesario en primer lugar establecer reglas para calcular el precio justo y luego apreciar en qué medida su variación era aceptable. En general el precio justo se determinaba por la equivalencia propuesta por Aristóteles, fijada de buena fe por un grupo de hombres correctos. Sin embargo, en la medida en que el juego libre de oferta y demanda producia variaciones (por ej. la abundancia o la carencia de un bien, el monopolio, etc.) estaba claro que pocas eran las transacciones que cumplían exactamente el requisito del precio justo. En el otro extremo, una diferencia de más del $50 \%$ era considerada francamente injusta. En el intermedio, una infinidad de matices aguardaban soluciones casuísticas. Así, mientras que los mendicantes se negaron a aplicarse personalmente dichas reglas (incluso en sus salarios profesionales como académicos de las universidades), admitieron la justicia de considerar como valor (crédito) el riesgo, el uso de las cosas y hasta del tiempo.

En este contexto racionalizador de las ideas de la tradición, el dinero fue pensado en términos de instrumentalidad, y tal consideración, de caracter más filosófica que teológica, signó sin duda el enfoque teológico de los tratados morales sobre la usura. Santo Tomás definió al dinero como medio de intercambio y este criterio fue adoptado regularmente por su posteridad. Las consecuencias de tomar seriamente tal concepto son claras. Si el dinero es un medio de intercambio y el intercambio es un bien, el hecho de comprar por menos y vender por más (intercambio) no es necesariamente malo o ilegítimo. Porque ese trabajo de intercambiar, de favorecer la circulación de los bienes necesarios tiene un precio (en función del tiempo, del esfuerzo, del riesgo, etc. que conlleva) que se suma al precio de compra resultando así el precio de venta. Esta idea está presente en todos los autores franciscanos desde Alejandro de Hales; la usa explícitamente Olivi ${ }^{16}$ e implícitamente Alejandro de Alejandria, cuya obra ha sido tan importante en el contexto mendicante del s. XIV..$^{17}$ Inclusive para fundamentar estas nuevas ideas en los Santos Padres, se recurría a la distinción agustiniana entre el profesional y la profesión: un

16 "De emptionibus et venditionibus" (ed. Todeschini) p. $67 \mathrm{ss.} \mathrm{Partiendo} \mathrm{de} \mathrm{que} \mathrm{la} \mathrm{justicia} \mathrm{exige} \mathrm{equi-}$ dad (igualdad de prestaciones) y de que no hay un "precio" del uso del dinero diferente del dinero mismo, expone los requisitos de dicha equidad por la parte del acreedor, donde se incluye un amplio tratamiento de estas dudas. Puede decirse que el principio general es que hay usura cuando hay aprovechamiento de la posición más fuerte ( $7^{a}$ consideración, p. 85).

17 Sobre las relaciones de Alejandro con sus antecesores y sucesores, v. Alonzo M. Hamelin, Le tractatus de usuris de Maitre Alexandre d'Alexandrie, Roma, Pont. Ateneo Antonianum, 1955, p. 21 ss. 
mercader puede ser deshonesto, pero eso no implica que todo acto comercial lo sea. ${ }^{18}$ Siguieron específicamente esta idea Hugo de Saint-Cher y Eudes Rigaud entre los franciscanos.

En síntesis, podemos decir que a fines del s. XIII estaba aceptada la licitud del comercio y generalizada entre los teóricos la idea de que un comerciante honesto puede ser un buen cristiano. Con ello, los escolásticos habian variado fundamentalmente el antiguo concepto de usura. Mientras que hasta fines del s. XII todo pago de un crédito superior a la cantidad original era usura, ya el s. XIII se admite algún interés legítimo (como se ve por las citaciones conciliares) y en el s. XIV se procurará establecer reglas claras de licitud.

Esto no significa que el concepto de usura desapareciera, sino que el contexto de su aplicación variaba. Usura seguía siendo, como decía Santo Tomás, la venta simultánea de la propiedad y del uso del dinero y como tal era un ilícito, un fraude. Pero no toda diferencia entre el préstamo y su devolución es doble venta, precisamente el interés legítimo queda excluido del supuesto porque es propiamente un pago a cambio de un servicio diferente de la propiedad misma del dinero prestado. Esto se vincula a la problemática en torno al concepto de propiedad monetaria que veremos en el próximo apartado.

Veamos finalmente de qué modo la Escolástica del XIII concibió el interés. En el Derecho Romano este concepto, tal como hoy lo entendemos (en forma muy aproximada a los autores del doscientos) no existía. Lo que existía era un suplemento o pena pecuniaria que debía pagar el deudor moroso. Este título extrínseco, que como tal no integraba el préstamo, sino que constituía una transacción en sí mismo, tenía sus propias calificaciones jurídicas y morales según sus propias circunstancias. El primero en estudiar sistemáticamente la validez moral de los títulos extrínsecos fue Roberto de Courçon, quien en su Tratado sobre la usura admitió la pena pecuniaria, pero estimó que no debía pagarse al prestamista sino distribuirse entre los pobres. ${ }^{19}$ Pensador de fines del XII, todavia no asimila la cuestión del interés sino que lo conceptúa sólo desde el punto de vista de un deudor de mala fe. Desde principios del XIII se aceptó la licitud del interés por retraso. ${ }^{20}$ Así lo sostuvieron Alejandro de Hales, Juan de la Rochelle y Tomás de Aquino y finalmente el canónigo Hostiensis aprobó la moralidad del lucrum cessans. La sistemática moral del Aquinate, que tenía puntos en común con las ideas franciscanas, influyó también en Juan de Friburgo (m. 1314) cuya Summa confessorum sigue el plan de la obra de Raimundo, pero incluyendo material jurídico y del Hostiensis. La parte sistemática está tomada de la "Secunda Secundae" tomista.e integrada en un marco casuístico y jurisdizante. El Confessionale es una obra de difusión que trata simplificadamente las materias de la Summa. Dentro de los pecados capitales trata la avaricia y en ese contexto las cuestiones económicas. Aunque estas orientaciones teológico prácticas no son ideales para la profundización teórica de los temas de ética económica, la importancia de estas obras es que recogen y divulgan los resul-

18 Enn. Ps. LXX, PL 38, 866.

19 Robert de Courçon, Le traité "de usure", ed. G. Lefèvre, Lille, 1902.

20 Little, Pobreza voluntaria y economía de beneficio, cit. p. 221 ss. 
tados más importantes de la teorización del s. XIII. ${ }^{21}$ Es así como una materia controvertida en el s. anterior y objeto de largos tratamientos, adquiere consenso más generalizado. El caso más interesante de este nuevo enfoque es el extracto de la Summa confessorum de Juan de Friburgo realizado por un fraile dominico de nombre Guido, y que trata específicamente de los mercaderes y la usura. Observa Lit$t^{22}$ que la importancia de esta obra es que no se condena el comercio en general y vagamente, como solía hacerse hasta el s. XIII, sino sólo algunas actividades muy concretas. Otro signo concreto del cambio de los tiempos es para Little ${ }^{23}$ el hecho de que los intereses por daño emergente, que en general quedaban incluídos en las condenas conciliares, en el s. XIII y en adelante se escribían y contabilizaban en los libros de comercio, convirtiéndose así en práctica habitual en vez de algo desviado y ocultable, como antes (los usurarii manifesti).

Sin embargo, llegamos a fines del XIII sin tener una teoría complexiva de estos títulos extrinsecos (retraso, daño emergente, lucro cesante, etc.). El efecto de estas situaciones inicialmente excepcionales era justificar el cobro de hecho de un interés razonable teniendo en cuenta la competitividad del mercado. En definitiva, llámese interés en nuestro actual sentido o no, se trataba de beneficios comerciales cuya licitud se aseguraba. Esta es la actitud de Gil de Lesines, dominico, y de Pedro Juan Olivi y Alejandro de Alejandría (o Alejandro Lombardo), franciscanos, es decir, todos mendicantes que por vocación propia habían renunciado a toda propiedad y beneficio.

Muy importante fue, en la literatura de esta época, el Tractatus de usuris de Alejandro de Alejandría, probable producto de una polémica oral habida en Génova en 1307. Esta obra ha sido cuidadosamente estudiada por A. Hamelin. ${ }^{24}$ Compulsando sus fuentes, se aprecia que Alejandro no innovó en ellas sino que hizo uso de los textos habituales y tuvo en cuenta la literatura inmediatamente anterior. Su originalidad radica en que se centró en el estudio de casos, siguiendo una línea iniciada por Gil de Lessines. Discutió doce casos de legitimidad del interés y una serie de casos dudosos. En su concepto, el dinero no puede ser vendido, lo que se vende es el derecho al dinero y el interés sería el precio de la duda (o del riesgo) del futuro pago. En el mismo sentido hay que mencionar otro franciscano, Francisco de Meyrones. ${ }^{25}$

Por otra parte, no puede negarse que esta nueva situación produjo efectos ambivalentes. Junto a las justificaciones éticas del uso financiero del dinero, aparece una literatura contradictoria, representada incluso iconográficamente por figuracio-

21 A fines del XIII y principios del XIV Scoto recoge toda esta elaboración en un contexto que se aproxima al modemo, lo que permitió a la escuela franciscana su aplicación hasta tiempos recientes (cf. Francesco Bettazzi, "Del mutuo e della usura e una opinione del Dottore Sottile", Studi Francescani 8, n. 3, 1922: 245-266).

Ob. cit. p. 241.

23

24

Ibid. p. 261:

Ob. cit. p. 24-34.

En otra línea, San Antonino de Florencia OP. - mediados del XIV - en su Summa Theologica, que es un tratado de moral, se ocupa de estos temas económicos en función del pecado de avaricia, es decir, manteniendo todavia los criterios usuales hasta la mitad del s. XIII (cf. José L. Mlanes y J. I. Saranyana, Historia de la Teología, Madrid, BAC, 1995, p. 106). 
nes anales y excrementísticas. La idea de que el dinero es algo sucio no es original de esta época pero tampoco es exceșivamente antigua. Todavía en los ss. IX y X, en tiempos del nuevo imperio, la moneda era vista como un símbolo imperial. En los siglos siguientes, particularmente el XII, hay un viraje concomitante a la descalificación de la usura y a la inquina contra los usureros que tanto ha perjudicado a los judíos, sobre todo en la península hispánica.

Es importante señalar que no siempre los religiosos fueron enemigos del dinero. Al contrario, se sabe que los monjes lo utilizaban normalmente, controlando las ferias y los mercados rurales que se iban formando en sus inmediaciones. ${ }^{26}$ Aunque habitualmente no invertian sus riquezas en empresas urbanas, no puede decirse que lo anatematizaran. El recelo explícito al dinero provino más bien del clero rural marginado, de algunas sectas extremosas y en definitiva de la inquina propia de los desfavorecidos. Los más críticos de todos ellos fueron los ermitaños de los ss. XI y XII, que iniciaron una predicación itinerante predecesora de los movimientos pauperísticos de fines del XII y comienzos del XIII. Pero a fines de este siglo y comienzos del XIV estas actitudes eran minoritarias. Los problemas, como he dicho, se relacionaban con las reglas para repartir justicieramente los bienes y los procedimientos más eficaces para atender a los pobres.

\section{B. La propiedad del dinero}

El concepto de dominio fue central en el derecho romano. Las relaciones jurídicas vinculadas a las cosas se basan en este concepto. Por otra parte, las relaciones entre las personas, en virtud de las cuales se obligan entre sí a determinados efectos, dió origen al gran capítulo de las obligaciones civiles, cuya especie más rēlevante son los contratos. La sistemática romana de los contratos fue tan completa que poco es lo que en esa línea se añadió después. Pero en la visión romanista clásica, las relaciones de los hombres entre sí se regían por el derecho contractual (o en general obligacional) y las relaciones con las cosas por el patrimonial. Es cierto que había algunas excepciones, por ej. el dominio sobre personas, pero es sintomático que para poder tratarlas el derecho romano las asimilaba a las cosas. No había un concepto específico de propiedad para las cosas no susceptibles de "apropiación". ¿Qué clase de realidad jurídica es el dinero? Este es un problema que se debate hasta hoy. Cualquiera sea la teoría jurídica que se elija, está claro que debe ser acorde, al menos en principio, con la realidad económica del dinero. Precisamente la dificultad de concebir la "apropiación" con conceptos diferentes de los romanísticos - y el dinero sin duda es susceptible de apropiación - llevó a aplicarle la distinción entre propiedad y uso, como en derecho romano se hacía con las cosas. Siendo en principio distintas la propiedad y el uso, no sólo conceptual sino también realmente, una persona podia ser dueña de la propiedad y otra del uso de una cosa, por ej. de una finca o de un caballo. Si aplicamos este criterio al dinero, como efectivamente se hizo, resulta que una es la propiedad y otra el uso del dinero. Pero ¿qué es la propiedad del dinero' sin el úso? El dinero es una realidad en que propiedad y uso se identifican pues la esencia propia del dinero implica su uso y no hay

26 Little (Pobreza voluntaria y economía de beneficio, cit. p. 90-91) dice que los monjes vendian sus excedentes en los muelles y prestaban dinero a los nobles. 
uso del dinero sin propiedad del mismo. De ahí que los escolásticos, siguiendo a los maestros del XII, extrajeron un argumento contra el interés: dado que propiedad y uso del dinero se identifican, quien vende por una parte la propiedad y por otra el uso vende lo mismo dos veces, contra toda regla de justicia. El razonamiento es correcto, supuestas las bases. Ocurre que se llegó a esa conclusión interpretando que el interés es el precio del uso. Es natural que si alteramos este concepto, también varíe la cuestión de la licitud del interés y con ella, la de la usura.

Por otra parte, aun admitiendo la licitud de algún interés, sigue en pie la cuestión usuraria, pero con una forma totalmente nueva. Al no identificarse interés y usura, ésta será el interés ilícito, por excesivo, desproporcionado o fraudulento. Pero esta situación ¿debe determinarse en cada caso o pueden establecerse ciertas reglas generales acerca de ello? Podemos decir aquí, una vez más, que los esfuerzos de los tratados mendicantes del s. XIV se orientan precisamente en la línea de establecer reglas que ayuden a los confesores y a los fieles en la determinación de los casos concretos de usura. Reglas que se transforman insensiblemente, al ser formuladas positivamente, en un código deontológico del comercio o de las finanzas.

\section{Conclusión}

Puede explicarse así por qué la reflexión mendicante contribuyó directamente a la elaboración de nuevas ideas, sin renunciar en absoluto a los postulados de perfección evangélica de sus santos fundadores. Los franciscanos, que tuvieron una ardua batalla interna por el tema de la pobreza y el beneficio, fueron sin duda los más sensibles al tema, y lograron en el s. XIV un buen equilibrio entre los requerimientos naturales y obvios del medio urbano en que actuaban y sus propias ideas de imitadores de San Francisco. Podemos pues acordar con Gilchrist que las conclusiones de algunos investigadores como Taewney deben ser reconsideradas. ${ }^{27}$ En general, muchos historiadores no han tenido en cuenta los elementos legitimantes del pensamiento escolástico y se asocian demasiado rápidamente a las tesis de Weber, explicando las condenas a la usura en el contexto de economía de subsistencia y no de producción. Sin embargo en el s. XIII muchas ciudades tenían prósperos comercios y los mendicantes tuvieron en cuenta esa realidad. La tesis del origen calvinista del capitalismo moderno debe ser corregida en cuanto a la cronología (el proceso se inicia por lo menos dos siglos antes) y también debe ser adecuadamente matizada.

27 CF: The Church and Economic Activity in the Middle Ages, London, New York, 1969 (p. 131). Señala también que el punto de vista de Weber no puede extremarse: en 1541 Calvino condenó la usura en Ginebra (p. 132). Por tanto su pensamiento es distinto del "efecto Calvino". 